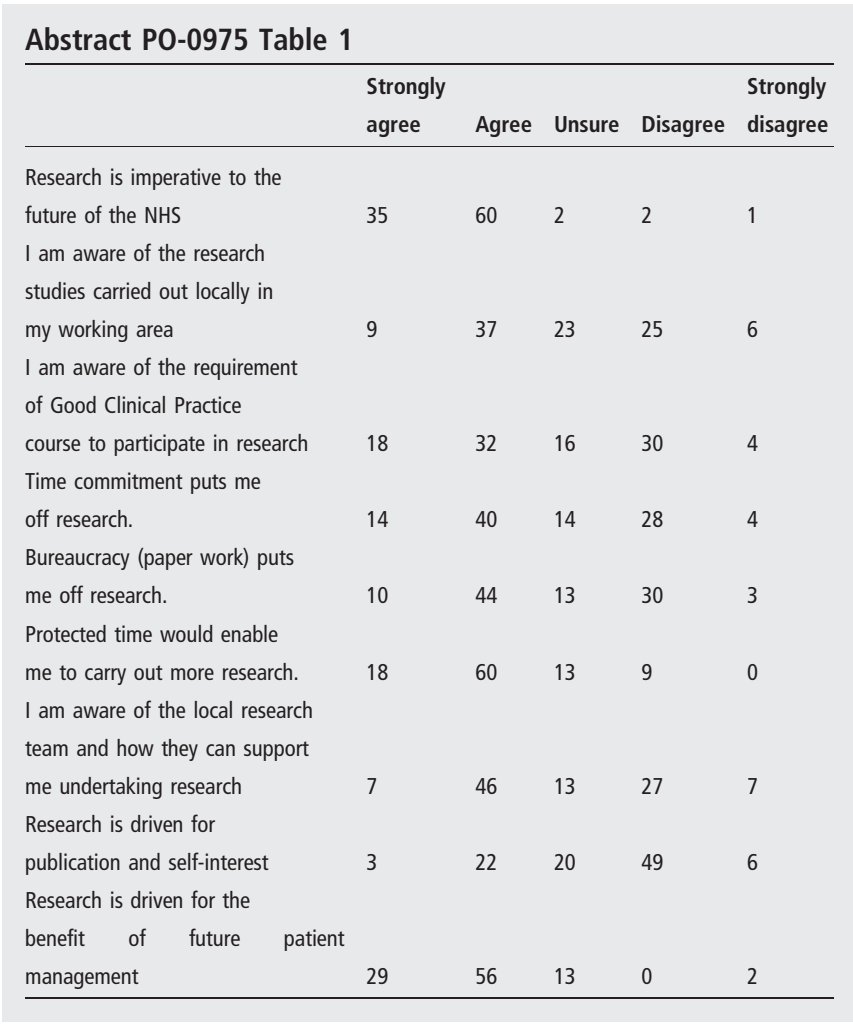

Aim To ascertain knowledge and attitude towards research and identify barriers amongst healthcare professionals in a district general hospital setting.

Methods All the healthcare professionals were emailed a questionnaire via 'survey monkey' in March 2014. An email reminder to non-respondents was sent 2 weeks later. Questions focussed on participant's knowledge and attitude towards research and identifying perceived barriers to undertaking research.

Results 87 responses were received (26 doctors and 61 allied health professionals). Following table outlines key study findings in $\%$.

Conclusions Majority of participants perceived time commitment and bureaucracy as barrier to research. Dedicated time allocated in the job plan and administrative support would be imperative in improving research outcomes leading to innovative treatments that can significantly improve patient health in future.

\section{PO-0976 PRESCRIBING IN THE ELECTRONIC AGE: FASTER, SAFER, BETTER?}

${ }^{1} \mathrm{P}$ Dale, ${ }^{2} \mathrm{P}$ Munyard. ${ }^{1}$ Pharmacy, Royal Cornwall Hospital, Truro, UK; ${ }^{2}$ Child Health, Royal Cornwall Hospital, Truro, UK

\subsection{6/archdischild-2014-307384.1594}

Background and aims In December 2012 electronic prescribing (EP) and administration of medicines was introduced to the Trust ( 800 beds, 40 paediatric beds, 3 Paediatric HDU beds, 20 admissions/day) as a pilot - specifically to the Child Health Department - before general adoption across the Trust.
Methods Pre-implementation, training was thoroughly and carefully organised for 40 paediatricians, 60 nurses and 5 pharmacists. Training was face to face and then on-line with face to face support. Mobile computing devices were distributed to the ward areas. All in-patient paper prescriptions were transcribed to electronic systems and paper prescriptions were removed. Ward based $24 \mathrm{~h}$ pharmacist/nurse support was available for the first week.

Results All prescriptions were legible.

Antibiotic stewardship easily audited - prescriptions with stop/review date 50\%/indication $33 \%$ vs. $86 \% / 80 \%$ respectively after an educational programme in child health.

No paediatric patients have been given a medication to which they were known to be allergic after implementation of EP.

Dispensary error rates from electronic prescription orders reduced from $5.38 /$ month to $1.5 /$ month post-implementation.

Only $25 \%$ of paediatric staff would go back to paper prescriptions.

The system is now adopted across most of the Trust.

Conclusions Departmental involvement in planning was most important as was "buy-in" from the junior doctors and nursing staff. Well organised training for all staff, intensive and face-toface, is felt to be essential. EP has been accepted and is a safer system which enables audit of practice down to individual levels. Outpatient use is planned in the future.

\section{PO-0977 WITHDRAWN}

\section{PO-0978 POPULATION-BASED STUDY OF DOWN SYNDROME PREVALENCE IN SOUTHERN THAILAND}

${ }^{1} \mathrm{~S}$ Jaruratanasirikul, ${ }^{1} \mathrm{O}$ Kor-anantakul, ${ }^{2} \mathrm{~W}$ Limpitikul, ${ }^{3} \mathrm{P}$ Dissaneevate, ${ }^{3} \mathrm{~S}$ Sutthibenjakul, ${ }^{4} \mathrm{~N}$ Khunnarakpong, ${ }^{4} \mathrm{~N}$ Intharasangkanawin, ${ }^{5} \mathrm{~A}$ Sattapanyo, ${ }^{5} \mathrm{~S}$ Pathompanitrat. ${ }^{1}$ Pediatrics, Prince of Songkla University, Songkhla, Thailand; ${ }^{2}$ Pediatrics, Medical Education Center Songkhla Hospital, Songkhla, Thailand; ${ }^{3}$ Pediatrics, Medical Education Center Hatyai Hospital, Songkhla, Thailand; ${ }^{4}$ Pediatrics, Medical Education Center Trang Hospital, Trang, Thailand; ${ }^{5}$ Pediatrics, Phatthalung Hospital, Phatthalung, Thailand

\subsection{6/archdischild-2014-307384.1595}

Introduction Down syndrome (DS) is the most common chromosomal disorder that causes mental retardation. In Thailand, studies on DS from 1969-1978 and 1988-1999, both hospitalbased, found prevalences of DS of 0.89 and 1.07 per 1,000 live births.

Objective To determine the prevalence of DS in the populationbased birth defect registries in 3 provinces in southern Thailand (Songkhla, Trang, Phatthalung), and the proportion of termination of pregnancy (ToP) of DS fetuses detected by prenatal screening.

Method Data were obtained from a population-based surveillance study undertaken during 2009-2012. Entries in the birth defects registry included all live births, all stillbirths, and all ToPs following a prenatal diagnosis. Infants with clinical characteristics of DS had a chromosomal study to make a definite diagnosis.

Results Of the total 148,795 births recorded during the study period, 180 DS cases were listed, giving an average prevalence of 1.21 per 1,000 births. The median maternal age was 36.4 years with percentage of maternal age $\geq 35$ years of $52.2 \%$ (94/ 180). Fifty-three cases (29.4\%) diagnosed prenatally resulted in termination of pregnancy. 